\title{
On the Mechanisms Governing Aluminum-Mediated Solid-Phase Epitaxy of Silicon
}

\author{
YANN CIVALE, ${ }^{1}$ GUGLIELMO VASTOLA,${ }^{2}$ LIS K. NANVER,,${ }^{1,4}$ \\ RANI MARY-JOY, ${ }^{1}$ and JAE-RYOUNG KIM ${ }^{3}$
}

\begin{abstract}
1.-Laboratory of Electronic Components, Technology and Materials, Delft Institute of Microsystems and Nanoelectronics (DIMES), Delft University of Technology, Feldmannweg 17, 2628 CT Delft, The Netherlands. 2.-L-NESS and Department of Materials Science, MilanoBicocca University, Via R. Cozzi 53, 20125 Milan, Italy. 3.-Molecular Electronics and Devices, Kavli Institute of Nanoscience Delft, Delft University of Technology, Lorentzweg 1, 2628 CJ Delft, The Netherlands. 4.—e-mail: L.K.Nanver@tudelft.nl
\end{abstract}

Mechanisms governing the aluminum-mediated solid-phase epitaxy of Si on patterned crystalline $\mathrm{Si}$ substrates have been identified by studying the deposited material as a function of growth conditions when varying parameters such as temperature, growth time, and layer-stack properties. Early growth stages can be discerned as first formation of "free" $\mathrm{Si}$ at the $\mathrm{Al} / \alpha-\mathrm{Si}$ interface, then diffusion of $\mathrm{Si}$ along the $\mathrm{Al}$ grain boundaries, nucleation at the Si substrate surface, nuclei rearrangement, and finally crystal growth. The acquired understanding is applied to control the selectivity and completeness of single-crystal growth in various sizes of contact windows to the Si substrate.

Key words: Aluminum doping, aluminum-induced crystallization, layerexchange mechanisms, low-temperature doping, $p^{+}-n$ diodes, silicon crystal growth, silicon epitaxy, solid-phase epitaxy

\section{INTRODUCTION}

Today low-temperature silicon crystallization techniques are receiving a lot of attention because of the potential for fabricating electronic semiconductor device building blocks for applications such as thin-film transistors, solar cells, and semiconducting nanowires. In particular, mechanisms leading to the formation of polycrystalline silicon thin films have been investigated intensively over the past few years. The crystallization of amorphous silicon $(\alpha-\mathrm{Si})$ can be driven by a reduction in Gibbs free energy, a process that can be energetically enhanced by the presence of a metal layer such as nickel $(\mathrm{Ni})^{1}$ or aluminum $(\mathrm{Al})^{2}$. For example, the activation energy for solid-phase crystallization of $\alpha-\mathrm{Si}$ of about $2.7 \mathrm{eV}^{3}$ is reduced to about $0.8 \mathrm{eV}$ when the semiconductor is in contact with $\mathrm{Al}^{4} \mathrm{~A}$ generally accepted mechanism of crystallization based on

(Received May 19, 2008; accepted June 11, 2009;

published online July 7, 2009)
$\alpha-\mathrm{Si} / \mathrm{Al}$ layer exchange has been used to describe the growth of polycrystalline $\mathrm{Si}$ on foreign substrates in this situation. ${ }^{5-7}$

In previous studies, ${ }^{8,9}$ we reported a sub- $500^{\circ} \mathrm{C}$ selective Si solid-phase epitaxy (SPE) process using $\mathrm{Al}$ as a transport medium. On both patterned and nonpatterned crystalline Si substrates this process produced high-quality monocrystalline $\mathrm{Si}$ (c-Si) islands, which are uniformly doped with $\mathrm{Al} .{ }^{10}$ Focus was placed on the use of these $p^{+}$SPE-Si islands for the fabrication of devices containing $p^{+}-n$ diodes and $p^{+}$contacts. Device quality was found to be exceptionally good for a large range of device geometries and process parameters, including temperatures down to $400^{\circ} \mathrm{C}$.

In this study, the focus is on the mechanisms that govern the SPE-Si growth. An intensive study of the earliest growth stages and the dependence on the $\mathrm{Si}$ substrate orientation has been carried out, on the basis of which a semi-empirical growth model is proposed. Particularly, the time and substrate dependence of SPE-Si coverage is addressed in this 
study, as well as the fabrication parameters affecting the controllability of the selective growth. It is shown that the latter can be optimized for the selective filling of a wide range of geometries. In particular, the electrical characterization of SPE-Si based $p^{+} n$ ring-shaped diodes as large as $1 \mu \mathrm{m} \times 395 \mu \mathrm{m}$ is presented.

\section{EXPERIMENTAL PROCEDURES}

In one group of experiments, SPE was performed on bare Si wafers with (100), (110) or (111) orientation. In most of the experiments, (100)-Si substrates were patterned by first growing $30 \mathrm{~nm}$ of thermal silicon dioxide $\left(\mathrm{SiO}_{2}\right)$ in which contact windows to the $\mathrm{Si}$ are etched. In all cases, the preparation of the samples for the SPE growth sequence is as follows: the Si surface was first cleaned in a nitric acid solution $\left(\mathrm{HNO}_{3}\right)$ and the resulting native $\mathrm{SiO}_{2}$ was removed by dip-etching in diluted hydrofluoric acid (HF) $0.55 \%$ for $4 \mathrm{~min}$. This provides hydrogen-terminated surface passivation. Directly after dip-etching, wafer rinsing, and drying, a layer stack of $\mathrm{Al}$ (containing 1 at. $\% \mathrm{Si}$ ) and $\alpha$-Si was formed by physical vapor deposition (PVD) at $50^{\circ} \mathrm{C}$.

Both PVD depositions were performed using an argon flow of $100 \mathrm{sccm}$ and without breaking vacuum so that the formation of an insulating native aluminum oxide $\left(\mathrm{Al}_{2} \mathrm{O}_{3}\right)$ layer before the $\alpha$-Si deposition was prevented. The influence of an $\mathrm{Al}_{2} \mathrm{O}_{3}$ layer between the PVD thin films has already been investigated by many research groups for the case of aluminum-induced $\mathrm{Si}$ crystallization on $\mathrm{SiO}_{2}$. Particularly, Schneider et al. ${ }^{11}$ showed that the presence of such an insulating interface affects the growth by introducing a diffusion barrier to $\mathrm{Si}$ transport. This yields a slower $\mathrm{Si}$ crystallization process, resulting in the formation of larger polycrystalline $\mathrm{Si}$ islands. The influence of such $\mathrm{Al}_{2} \mathrm{O}_{3}$ layers was not investigated in this study.

The bulk of the results presented herein correspond to thicknesses of the deposited $\mathrm{Al}$ and $\alpha$-Si thin films of $200 \mathrm{~nm}$ and $20 \mathrm{~nm}$, respectively. On the samples with contact windows through the oxide, the layer stack was patterned so as to cover the contact windows and extend around them by varying amounts, as shown in Fig. 1. The samples were then transferred to the annealing module, in which a thermal treatment in argon was performed at either $400^{\circ} \mathrm{C}$ or $500^{\circ} \mathrm{C}$. After annealing, the $\mathrm{Al}$ layer was removed selectively to $\mathrm{Si}$ and $\mathrm{SiO}_{2}$, using a conventional metal-etchant solution. The as-obtained surfaces were then analyzed by scanning electron microscopy (SEM) in order to identify the successive stages of the growth sequence and determine the dependence of the SPE-Si surface coverage on parameters such as the growth time, the $\mathrm{Si}$ source composition, and the substrate orientation.

In some cases, the $p^{+} \mathrm{SPE}-\mathrm{Si}$ islands were grown on $n$-type substrates so as to form $p^{+} n$ junctions. The anode and cathode (back of the wafer) were

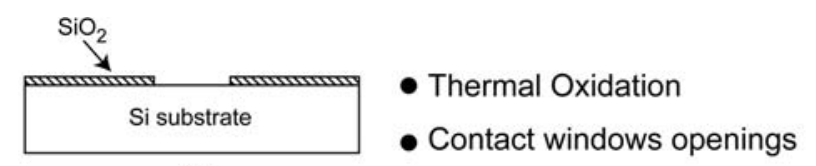

(1)

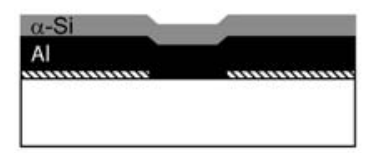

- Al/a-Si layer stack deposition

(2)

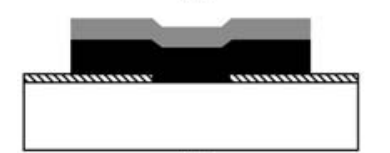

- Al/ $\alpha$-Si layer stack patterning

(3)

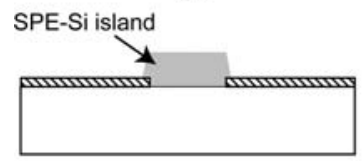

- SPE Annealing

- Aluminum removal

(4)

Fig. 1. Schematic process fabrication flow for the SPE-Si growth test structures. Contact windows are patterned and etched through thin $(30-\mathrm{nm})$ thermally grown $\mathrm{SiO}_{2}$ to the $\mathrm{Si}$ substrate.

contacted by PVD deposition of $\mathrm{Al} /(1 \% \mathrm{Si})$ and interconnect patterning on the front of the wafer as described in previous publications. ${ }^{8}$

\section{BASIC GROWTH MECHANISMS}

\section{Basic Growth Sequence}

A series of SEM images that illustrate the different stages of the SPE crystal growth are shown in Fig. 2. From this type of experimental observation, it has been possible to conclude that the growth sequence is composed of the following consecutive steps: (1) formation of "free" Si at the $\mathrm{Al} /$-Si interface, (2) diffusion of Si along the $\mathrm{Al}$ grain boundaries, (3) nucleation at the Si substrate surface, (4) nuclei rearrangement, and (5) crystal growth. Each of these stages is specified in Fig. 3 and addressed below in detail.

\section{Formation of "Free" Si Atoms}

As described by Hiraki's ${ }^{12}$ model, free electrons in the Al layer adjacent to the $\alpha$-Si first screen the $\mathrm{Si}$ covalent bonding and thus weaken the Si-Si bonds. The relatively weakly bonded $\mathrm{Si}$ atoms are called "free" Si because of their ability to migrate through the Al layer. It is generally accepted that such a screening effect only acts over a short range and will be restricted to the first two atomic monolayers of the $\alpha$-Si layer. The formation of such "free" Si atoms is indirectly substantiated by the experimental observation that, after long-term annealing of the $\mathrm{Al} / \alpha-\mathrm{Si}$ layer stack, all that remains is a surface coverage of $\mathrm{Al}$ on the test structures, i.e., the deposited $\alpha$-Si has dissolved and diffused through the metal film. 

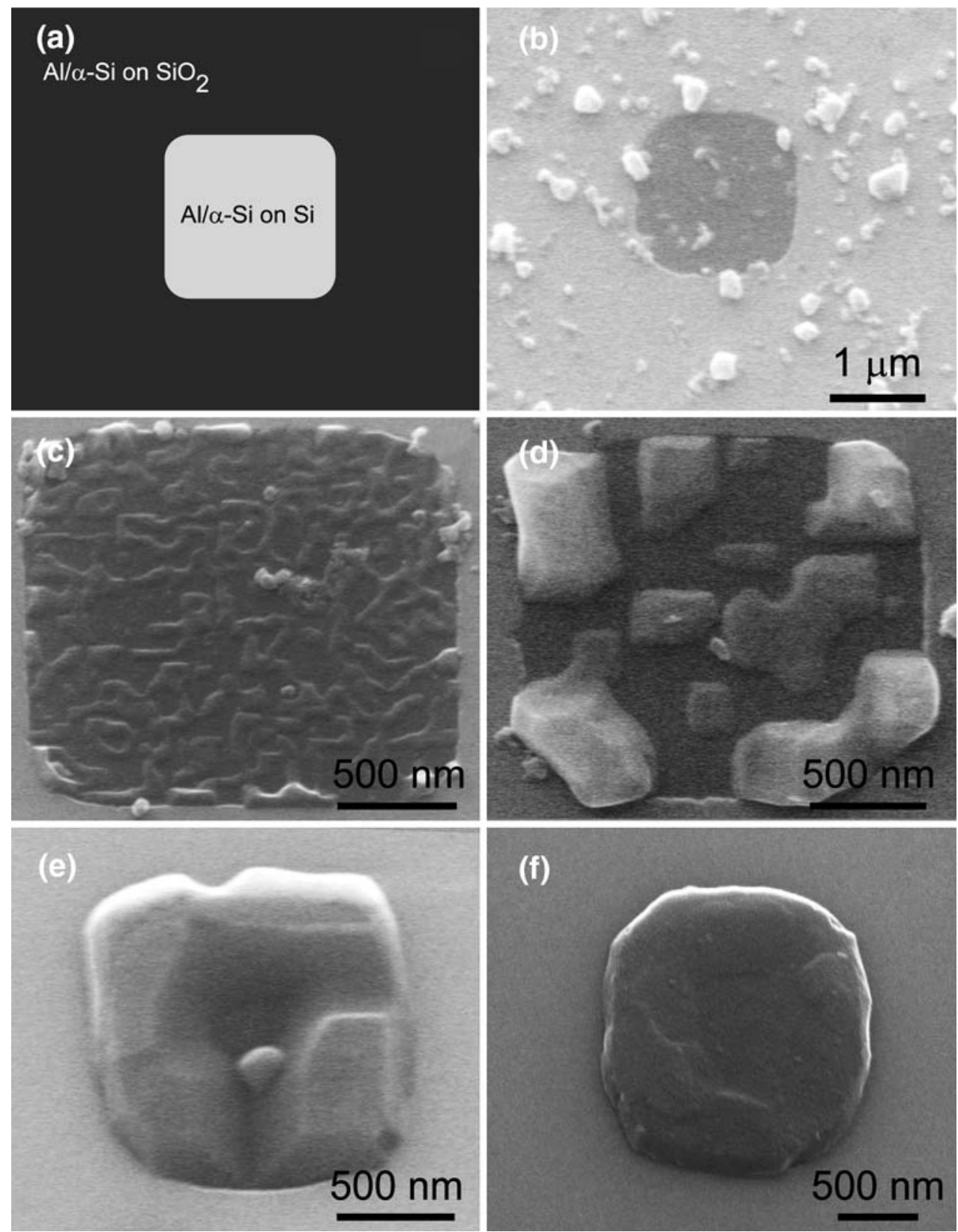

Fig. 2. (a) Schematic top view of the contact window (light-grey region) before SPE-Si growth. After the SPE growth and AI removal, SEM micrographs of the contact window region were analyzed after different growth times and temperatures: (b) $1.5 \mathrm{~min}$ at $500^{\circ} \mathrm{C},(\mathrm{c}) 2 \mathrm{~min}$ at $400^{\circ} \mathrm{C}$, (d) $6 \mathrm{~min}$ at $500^{\circ} \mathrm{C}$, (e) $30 \mathrm{~min}$ at $500^{\circ} \mathrm{C}$, and (f) $30 \mathrm{~min}$ at $500^{\circ} \mathrm{C}$. In the latter case, an optimal Al/ $\alpha$-Si layer stack geometry and thickness ratio has been used to obtain near-ideal growth selectivity.

\section{Diffusion Through the Al Grain Boundaries}

The $\mathrm{Al}$ layer, deposited by PVD at $50^{\circ} \mathrm{C}$, is microcrystalline and contains a high density of grain boundaries. ${ }^{13}$ Thus, Si can diffuse either: (1) through the $\mathrm{Al}$ grains, (2) along the $\mathrm{Al}$ grain boundaries, (3) along the $\mathrm{Al}$ to the $\alpha$-Si interface or (4) along the $\mathrm{Al}$ to the Si-substrate interface. The diffusion path along the $\mathrm{Al}$ grain boundaries is known to be predominant in the early stages of thermal treatment of $\mathrm{Al} / \mathrm{Si}$ alloys. ${ }^{14}$ Thermodynamically, the occurrence of Si diffusion along the
Al grain boundaries is governed by the difference between the interface energies as given by

$$
2 \cdot \gamma_{\langle\mathrm{Al}\rangle-\{\mathrm{Si}\}}-\gamma_{\langle\mathrm{Al}\rangle}
$$

where $\gamma_{\langle\mathrm{Al}\rangle-\{\mathrm{Si}\}}$ is the interface energy between the $\mathrm{Al}$ and $\alpha$-Si layers and $\gamma_{\langle\mathrm{Al}\rangle}$ is the grain boundary energy of Al. Following methods previously reported by Wang et al., ${ }^{5} \gamma_{\langle\mathrm{Al}\rangle-\langle\mathrm{Si}\rangle}$ and $\gamma_{\langle\mathrm{Al}\rangle}$ were calculated at $500^{\circ} \mathrm{C}$, and found to be $2.85 \times 10^{-2} \mathrm{~J} \mathrm{~m}^{-2}$ and $3.5 \times 10^{-1} \mathrm{~J} \mathrm{~m}^{-2}$, respectively. This establishes that there is a positive driving force for the inward 


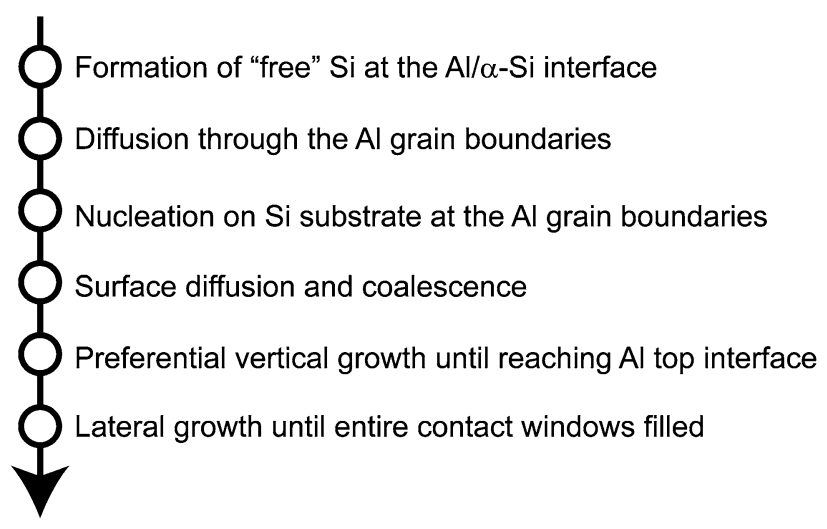

Fig. 3. The SPE-Si growth sequence.

diffusion of $\mathrm{Si}$ along the $\mathrm{Al}$ grain boundaries. A preference for the diffusion of $\mathrm{Si}$ along the $\mathrm{Al}$ grain boundaries is manifested by the shape and overall pattern of the deposited $\mathrm{Si}$ in the coalescence stage discussed below.

\section{Nucleation and Coalescence}

$\mathrm{He}$ et al. ${ }^{15}$ reported the existence of a critical $\mathrm{Si}$ thickness, $h_{\mathrm{c}}$, above which $\mathrm{Si}$ crystallizes. The value of $h_{\mathrm{c}}$ depends on the crystallization energy of $\alpha-\mathrm{Si}$, $\Delta G_{\langle\mathrm{Si}\rangle-\{\mathrm{Si}\}}$, and on the interface energy of $\mathrm{Al}$ with respect to the amorphous and crystalline $\mathrm{Si}$ interface, $\gamma_{\langle\mathrm{Al}\rangle-\{\mathrm{Si}\}}$ and $\gamma_{\langle\mathrm{Al}\rangle-\langle\mathrm{Si}\rangle}$, respectively, as given by the relationship

$$
h_{\mathrm{c}}=\frac{2 \cdot\left(\gamma_{\langle\mathrm{Al}\rangle-\langle\mathrm{Si}\rangle}-\gamma_{\langle\mathrm{Al}\rangle-\{\mathrm{Si}\}}\right)}{-\Delta G_{\langle\mathrm{Si}\rangle-\{\mathrm{Si}\}}} .
$$

In our case $h_{\mathrm{c}}$ is about $0.56 \mathrm{~nm}$, which corresponds to approximately 2.5 atomic monolayers, i.e., it is much smaller than the thickness of the deposited $\alpha$-Si thin film. Accordingly, $\alpha$-Si does not remain in a stable amorphous phase at the grain boundaries and will crystallize upon reaching the $\mathrm{Si}$ or oxide surface. This nucleation stage of the growth process was observed in our experiments after an annealing time of $1.5 \mathrm{~min}$ at $400^{\circ} \mathrm{C}$. It is characterized by a fine distribution of deposited Si nuclei, the shape of which displays no preferential orientation, both on the $\mathrm{Si}$ substrate and the oxide as illustrated by Fig. $2 \mathrm{~b}$.

As the Si diffusion along the grain boundaries progresses, both the number and the size of the Si nuclei increases until they impinge upon each other and merge. At $400^{\circ} \mathrm{C}$, the diffusion process is slow enough to allow the intermediate coalescence stage to be observed. This is shown in the SEM image in Fig. 2c, where the nucleated islands have coalesced to form a liquid-like pattern ${ }^{16}$ that follows the $\mathrm{Al}$ grain boundaries. This reflects the predominance of the diffusion along the $\mathrm{Al}$ grain boundaries in the early stages of the growth process, as predicted by Eq. 1.

\section{Growth on Nonpatterned Substrates}

After nuclei coalescence, larger Si crystals will form because the formation of additional Si-Si bonds corresponds to a lowering in energy. Quantitatively, this energy gain corresponds to the energy necessary for a new Si facet to be attached to the already formed Si crystal. To do so, four new Si-Si bonds have to be formed per unit cell. By the use of the binding energy given by the Tersoff potential ${ }^{17}$ for bulk Si of about $-4.62 \mathrm{eV}$, and assuming a facet width of $0.54 \mathrm{~nm}$, the energy gain corresponding to the formation of a new SPE-Si facet is approximately $-2.5 \mathrm{~J} \mathrm{~m}^{-2}$, which is much larger than the gain in energy from the formation of a Si-to-Al interface bond. This also means that there will be a tendency for the system to form large crystals since the free energy per atom (or per unit volume) decreases as the crystal volume increases.

The influence of the substrate orientation on the SPE has been investigated in the literature and a few already proposed models have demonstrated that the fastest growth rate is along the $\langle 100\rangle$ directions. $^{18}$ In particular, Drosd and Washburn ${ }^{19}$ formulated that the main criterion for $\mathrm{Si}$ in the amorphous phase to crystallize is the formation of at least two undistorted bonds with the crystal. On the basis of geometrical considerations, it can be concluded that this requirement is easily met in the (100) plane because one incoming Si atom can establish the necessary bonds. Along the (110) or (111) planes, however, the growth will be much slower because the bonds can only be achieved by the formation of a cluster of either two or three atoms, respectively. Several of our experiments reveal behavior that can be well understood in terms of this crystal growth criterion and they are described below.

Figure 4 shows SEM images of the results of SPE growth on nonpatterned substrates with an orientation of either (100), (110) or (111) as obtained after annealing at $400^{\circ} \mathrm{C}$ for $30 \mathrm{~min}$. The analysis of the (100) substrate after growth and $\mathrm{Al}$ removal shows that the SPE forms rectangular $\mathrm{Si}$ islands with sides parallel to the $\langle 110\rangle$ directions and with a height equal to that of the originally deposited $\mathrm{Al}$ layer, as shown in Fig. 4a. This is in agreement with a fastest growth rate in the $\langle 100\rangle$ directions because the direction perpendicular to the Si substrate surface is a $\langle 100\rangle$ direction. Moreover, according to the well-established Wulff theory, the final shape of a growing crystal is determined by the slowest growth direction. ${ }^{20}$ Thus, the fact that $\langle 110\rangle$ facets are exposed in the final growth stage also indicates a slower growth in the $\langle 110\rangle$ than in the $\langle 100\rangle$ direction. Most islands look square-like as would be expected from growth rate considerations, but a few are rectangular. This is feasibly connected to the varying accessibility of the sides with respect to the supply of silicon during growth of the crystal itself and the crystals in the vicinity. 

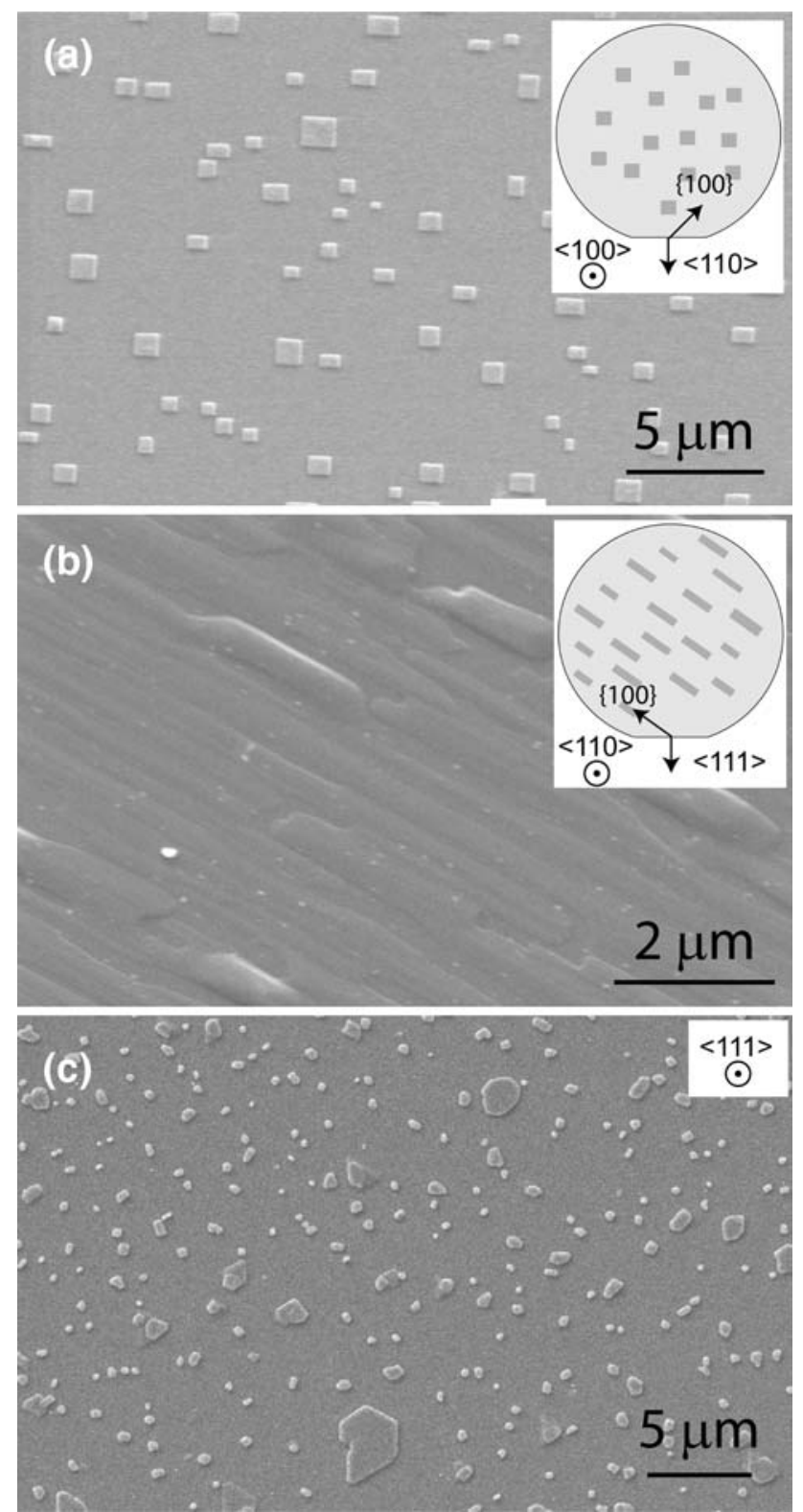

Fig. 4. Bare-Si substrate surface after SPE-Si growth and Al removal in the case of: (a) a (100)-oriented Si substrate, (b) a (110)-oriented Si substrate, and (c) a (111)-oriented Si substrate. In all cases, the growth temperature was $400^{\circ} \mathrm{C}$, the annealing time was $30 \mathrm{~min}$, and the $\mathrm{Al}$ and $\alpha$-Si thin film thicknesses were $200 \mathrm{~nm}$ and $20 \mathrm{~nm}$, respectively.

When the total surface occupied by SPE-Si islands is integrated for the situation shown in Fig. 4a and the island height is assumed to be within $7 \%$ of the deposited Al thickness, a total volume is found that corresponds well to the deposited volume of $\alpha$-Si. This agrees with the view that practically all the deposited $\alpha$-Si is crystallized by SPE. The vertical growth apparently stops when the SPE-Si height has reached the initial $\mathrm{Al}$ layer thickness. This feature will be addressed in more detail in the following section.
The results obtained on (110)-oriented substrates, illustrated in Fig. 4b, show discontinuous but micron-long stripe-like structures growing along the $\langle 100\rangle$ direction and essentially covering the whole of the sample surface. The height of these structures is a few tens of nanometers, which is far smaller than the $200 \mathrm{~nm} \mathrm{Al} \mathrm{layer.} \mathrm{Therefore,} \mathrm{it} \mathrm{would} \mathrm{appear} \mathrm{that}$ the fast growth in the $\langle 100\rangle$ direction has exhausted the supply of Si at the cost of the slower vertical growth in the $\langle 110\rangle$ direction. Electron backscattering diffraction analysis was performed on the (100)- and (110)-oriented Si samples and it was confirmed that the epitaxially grown $\mathrm{Si}$ preserves, in both case, the orientation of the substrate. The difference in shape of the SPE regions obtained on (100)- and (110)-oriented substrates (squares and rectangles, respectively) can be understood in terms of the balance between $\mathrm{Si} / \mathrm{Al}$ interface energy and the $\mathrm{Al}$ grain boundary energy. The vertical growth of $\mathrm{c}-\mathrm{Si}$ on (100) samples involves the formation of four new $\mathrm{Si}(110)$-to-Al interfaces. Keeping in mind relationship (1), the following relation holds:

$$
4 \cdot \gamma_{\langle(110)-\mathrm{Si}\rangle-\langle\mathrm{Al}\rangle}-\gamma_{\langle\mathrm{Al}\rangle}<0 .
$$

In contrast, the rectangular-shaped islands observed on $\mathrm{Si}(110)$ wafers tend to grow laterally rather than vertically: since this mechanism involves the creation of only two new Si-to-Al interfaces, it is an indication that relation (1) is here restricted to

$$
2 \cdot \gamma_{\langle(100)-\mathrm{Si}\rangle-\langle\mathrm{Al}\rangle}-\gamma_{\langle\mathrm{Al}\rangle}<0 .
$$

On the (111)-oriented substrate (Fig. 4c), only $\langle 111\rangle$ directions are available on the surface. Many structures, particularly the small ones, are irregular and do not exhibit any clear preferential growth directions. The density of islands is much higher and the average island surface area much smaller than for the (100)-substrate situation. This inadequate ability to coalesce into larger crystals is a clear indication that growth in the $\langle 111\rangle$ direction is difficult to initiate. However, island growth similar to that observed on the (100) sample is sporadically observed and a few large micron-sized islands can be found. For these it is possible to identify a preference for forming triangular-like shapes incorporating $120^{\circ}$ angles and a preferred growth from the corners of the crystals in the three $\langle 111\rangle$ directions. These larger islands have a height of $\sim 180 \mathrm{~nm}$, which is in good agreement with the targeted thickness of the deposited $\mathrm{Al} /(1 \% \mathrm{Si})$ layer, i.e., $200 \mathrm{~nm}$.

\section{Growth on Patterned (100) Substrates}

When SPE-Si islands are formed locally in contact windows, the mechanisms governing the SPE growth remain the same as for bare $\mathrm{Si}$. However, as seen in the SEM micrograph presented in Fig. 2d, the crystals grow predominantly at the contact 


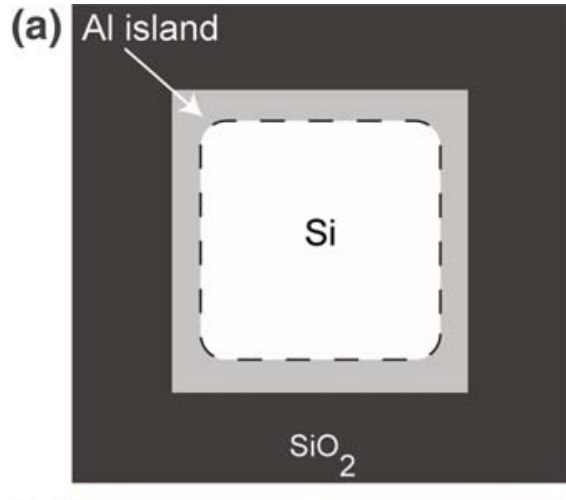

(b)

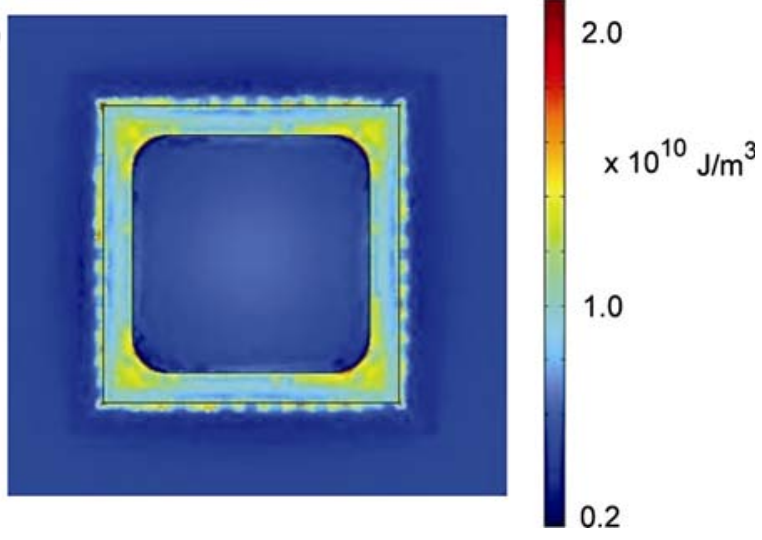

Fig. 5. FEM results showing the strain distribution in the Al thin film covering the contact windows opened through oxide, in the case of a fully strained Al thin film.

window perimeter. To evaluate whether this effect could be stress induced, finite-element modeling analysis was performed to evaluate the strain distribution in the as-formed $\mathrm{SPE}-\mathrm{Si} / \mathrm{SiO}_{2} / \mathrm{Al}$ structure. The results, illustrated in Fig. 5, indicate a reduction of the $\mathrm{Al}$ thin-film elastic energy field by a partial transfer of deformation to the oxide along the edges of the contact window. If it is assumed that the incoming $\mathrm{Si}$ is kinetically capable of traveling across the whole Al-to-Si window surface, the $\mathrm{SiO}_{2} / \mathrm{Si}$ interface would correspond, from a lattice deformation point of view, to a local minimum of the Si chemical potential found in the contact window, ${ }^{21}$ and this results in a preferential diffusion direction for the Si atoms. Moreover, the nucleation of c-Si at the window perimeter corresponds to the substitution of an $\mathrm{SiO}_{2} / \mathrm{Al}$ interface with an $\mathrm{SiO}_{2} / \mathrm{SPE}-\mathrm{Si}$ plus an SPE-Si/Al interface. The corresponding surface energies are $0.15 \mathrm{~J} \mathrm{~m}^{-2}$ and $0.3 \mathrm{~J} \mathrm{~m}^{-2}$, respectively. ${ }^{22}$ Since the $\mathrm{SiO}_{2} / \mathrm{SPE}-\mathrm{Si}$ interface is lower in energy than the SPE-Si/Al interface, it is natural for the system to try to maximize the exposure of the $\mathrm{SiO}_{2} / \mathrm{SPE}-\mathrm{Si}$ interface per unit volume, as illustrated in Fig. 6. Thus, it clearly follows from geometrical considerations that the deposition of $\mathrm{Si}$ at the corners of the contact windows is favorable.

As also observed on the nonpatterned samples, the SPE-Si island thickness is accurately controlled (a) $\mathrm{Si} / \mathrm{SiO}_{2}$ interface

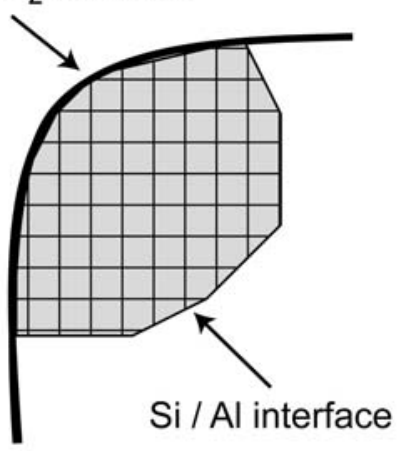

(b)

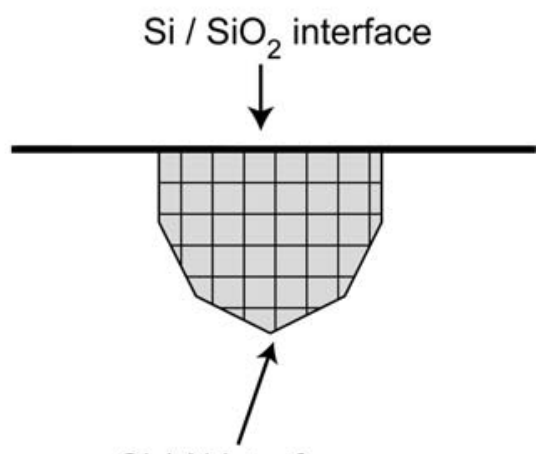

Si / Al interface

Fig. 6. Schematic of the SPE-Si deposition within the contact window: (a) at a corner and (b) along one of the sides. In both cases, the length of the SPE-Si/Al interface is identical.

by the height of the initial $\mathrm{Al}$ layer. If the growth of the SPE crystal was not limited in height by the $\mathrm{Al}$ layer, multifaceted crystals would be expected to grow in the manner that is commonly observed for other conventional Si epitaxy techniques. This has in fact been observed in the situation where the SPE growth is limited by the supplied $\mathrm{Si}$ and not the Al thickness. An example is shown in Fig. 7a where a $200-\mathrm{nm}$-wide contact window is filled by the $\mathrm{Si}$ supplied from a $200-\mathrm{nm}$-thick $\mathrm{Al} /\left(\begin{array}{lll}1 \% & \mathrm{Si}\end{array}\right)$ layer.

When a sufficiently large amount of Si is supplied, the vertical growth of SPE-Si, in the case of both bare Si and patterned samples, stops abruptly when the SPE-Si island reaches the thickness of the initial $\mathrm{Al}$, the multifaceting is inhibited and rectangular crystals form, among which the larger ones are very close to being perfect squares. This is in agreement with the results previously reported by Nast and co-authors ${ }^{24,25}$ for a layer-exchange aluminum-induced crystallization mechanism on glass substrates. During the SPE process, the Al film is segregated above the SPE-Si and forms an amorphous-like film like the one shown in Fig. $7 \mathrm{~b}$. The Al has a porous composition, very different from the polycrystalline $\mathrm{Al}$ composition of the $\mathrm{Al}$ in the original $\mathrm{Al} / \alpha-\mathrm{Si}$ layer stack. The results indicate that the $\mathrm{Al}$ that is segregated above the SPE-Si is no longer able to act as a transport layer for SPE 

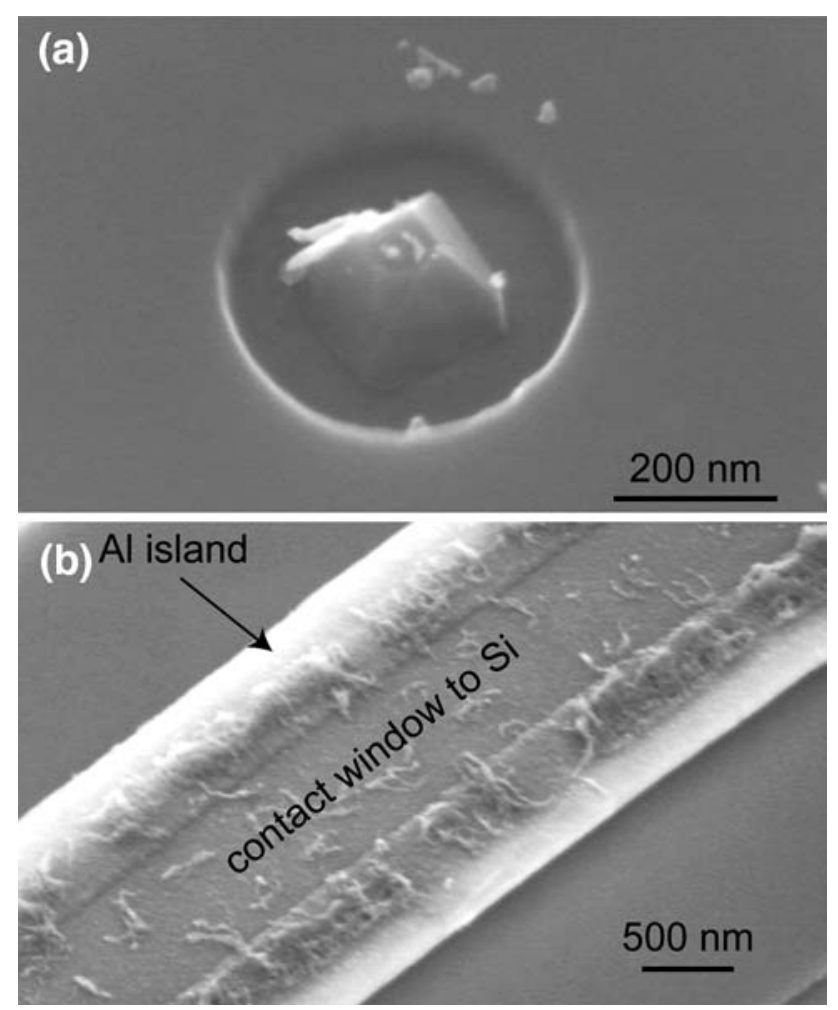

Fig. 7. (a) SEM micrograph of a $200 \mathrm{~nm} \times 200 \mathrm{~nm}$ contact window filled in with a faceted SPE-Si island. These dimensions were achieved by using a silicon nitride spacer technology. ${ }^{23}$ The source of Si was limited to the Si from a 200-nm-thick $\mathrm{Al}(1 \% \mathrm{Si})$ layer. (b) SEM micrograph of a contact window after being entirely filled with $\mathrm{SPE}-\mathrm{Si}$, and before the Al layer removal.

growth. Thus the SPE growth is terminated when the vertical growth of SPE-Si brings the Si into contact with the porous $\mathrm{Al}$.

Due to the low thickness of $\alpha$-Si used in our case (only $10 \%$ of the $\mathrm{Al}$ thickness), the SPE-Si growth is rapidly fed from the sides by diffusion of dissolved $\mathrm{Si}$ through the Al layer. While the Si diffuses through the $\mathrm{Al}$ grains, the $\mathrm{Al}$ is segregated on top of the grown SPE-Si island. Thus, supplying thicker $\alpha$-Si or wider $\alpha$-Si islands does not help to form a thicker thin film, since the SPE-Si island height is truncated when it reaches the initial $\mathrm{Al}$ layer thickness. The growth is stopped vertically and eventually tooth-like SPE-Si islands are formed, an example of which is shown in Fig. 2e. A very slight dent is observed in the middle of the island shown in Fig. 2f, which shows otherwise complete filling of the SPE window. Such a dent can be the result of the original $\mathrm{Al}$ topography or due to a lack of $\mathrm{Si}$ reaching the center of the structure. This may occur if the supply of Si from the sides is cut off by a completed vertical growth at the window perimeter or if too much Si crystallizes on the oxide rather than migrating to the contact window. The latter can be the result of nucleation on the dielectric or due to some measure of lateral overgrowth of the oxide from the SPE-filled contact window perimeter.

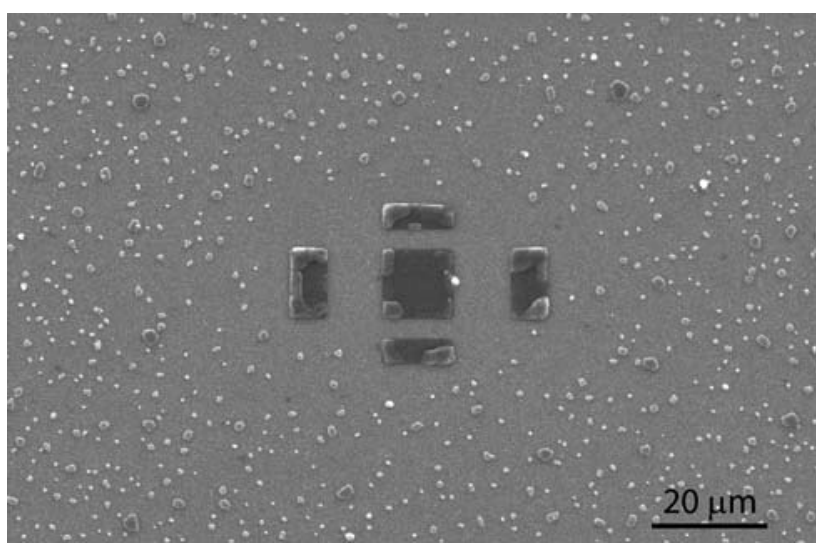

Fig. 8. SEM micrograph of five contact windows after 30 min growth at $500^{\circ} \mathrm{C}$ showing the preferred deposition on the $\mathrm{Si}$ in the contact windows.

As far as the Si nuclei on the oxide surface are concerned, they do not play a role as long as the $\mathrm{Si}$ is supplied close to the contact window and it is given time enough to diffuse to the contact window. The high diffusivity of the $\mathrm{Si}$ on the oxide can be observed indirectly as a reduction of the $\mathrm{Si}$ nuclei density on the exposed oxide surrounding the contact windows as the growth time increases. In Fig. 8 the situation for four neighboring contact windows covered by a nonpatterned $\mathrm{Al} / \alpha-\mathrm{Si}$ layer stack is shown. After a $30 \mathrm{~min}$ anneal at $500^{\circ} \mathrm{C}$, about a $7-\mu \mathrm{m}$-wide oxide region directly around the contact windows is free of Si nuclei.

\section{Surface Area Coverage}

The coverage of a contact window with SPE-Si as a function of annealing temperature and time was extracted from SEM images. The results are plotted in Fig. 9a for different $\mathrm{Al} / \alpha-\mathrm{Si}$ layer stack areas. Two distinct regions can be identified: first the SPE-Si coverage increases as the annealing time increases, which can be correlated to the growth behavior during the nucleation and the coalescence stages. Then the coverage remains constant (or slightly decreases) with further increase of the annealing time. This is accompanied by an increase in vertical growth, so the volume of deposited SPE-Si does significantly increase when the growth time is prolonged. This is in accordance with the drive to form compact structures and the fact that growth will preferably take place in the $\langle 100\rangle$ vertical direction perpendicular to the Si substrate surface. A constant coverage as a function of time is observed until the vertical growth is completed, i.e., when the SPE-Si island height reaches the thickness of the initial $\mathrm{Al}$ transport layer. At that moment the coverage starts to increase with time because the lateral growth on the $\mathrm{Si}$ and possibly also overgrowth of the oxide become predominant.

The SPE-Si coverage as a function of the width of the $\mathrm{Al} / \alpha-\mathrm{Si}$ layer stack area for an annealing time of 

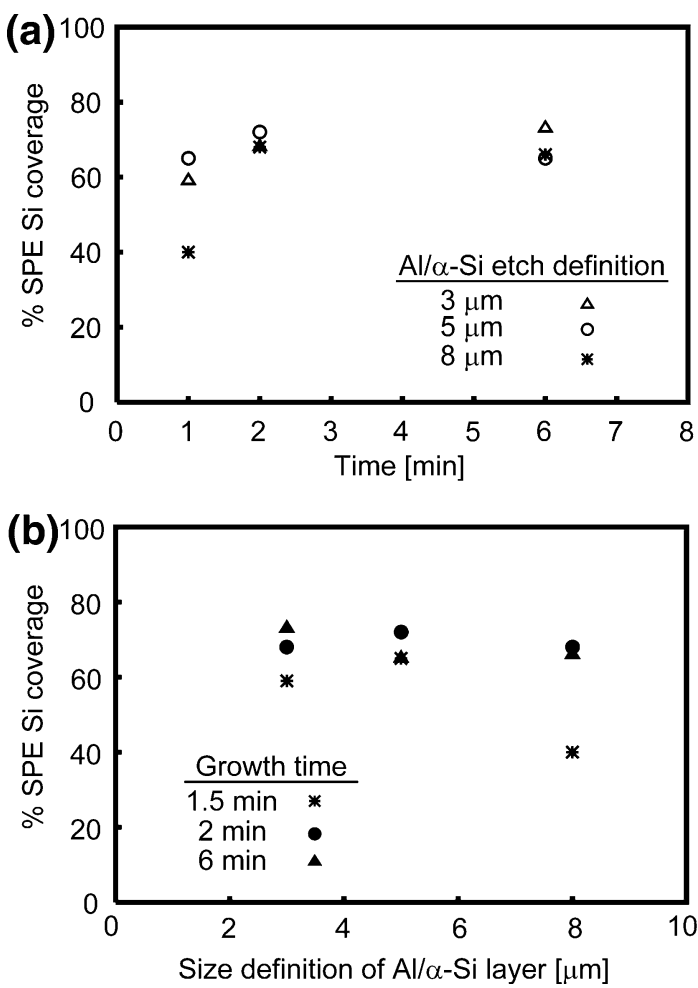

Fig. 9. Coverage of contact windows with SPE-Si as a function of (a) annealing time, and (b) $\mathrm{Al} / \alpha-\mathrm{Si}$ island area.

either $1.5 \mathrm{~min}, 2 \mathrm{~min}$, or $6 \mathrm{~min}$ is also plotted in Fig. 9b. The coverage is found to be nearly constant, irrespective of the $\mathrm{Al} / \alpha-\mathrm{Si}$ area. However, even though the surface coverage is nearly constant, the volume of created SPE-Si increases with the $\mathrm{Al} / \alpha-\mathrm{Si}$ area. This effect is related to the ability of the $\mathrm{Si}$ nucleated on the oxide to diffuse to the contact window. For the smallest $\mathrm{Al} / \alpha-\mathrm{Si}$ area $(3 \mu \mathrm{m} \times$ $3 \mu \mathrm{m})$, the region around the contact windows is smooth and apparently Si-free, indicating that the entire $\alpha$-Si layer has contributed to the vertical growth within the contact window. When the initial $\mathrm{Al} / \alpha-\mathrm{Si}$ area is much larger than the contact window, Si nucleation on oxide is observed for short growth times. In this case, the ratio of $\mathrm{Al} / \alpha-\mathrm{Si}$ layer to exposed oxide area is apparently so large that there is a significant probability that energetically favorable defects in the thermal oxide are found and given occasion to function as nucleation centers for the "free" Si atoms. Isolated polycrystalline Si islands can then grow. This will be discussed further in the following section. In general, it can be concluded that, if selective filling of the contact window is desired, the amount of exposed oxide surface should be as limited as possible. After a sufficiently long annealing time, typically $30 \mathrm{~min}$ for the $400^{\circ} \mathrm{C}$ anneal, the lateral growth progresses until the entire window surface is covered, provided that the $\alpha$-Si layer is thick enough to supply the necessary Si.
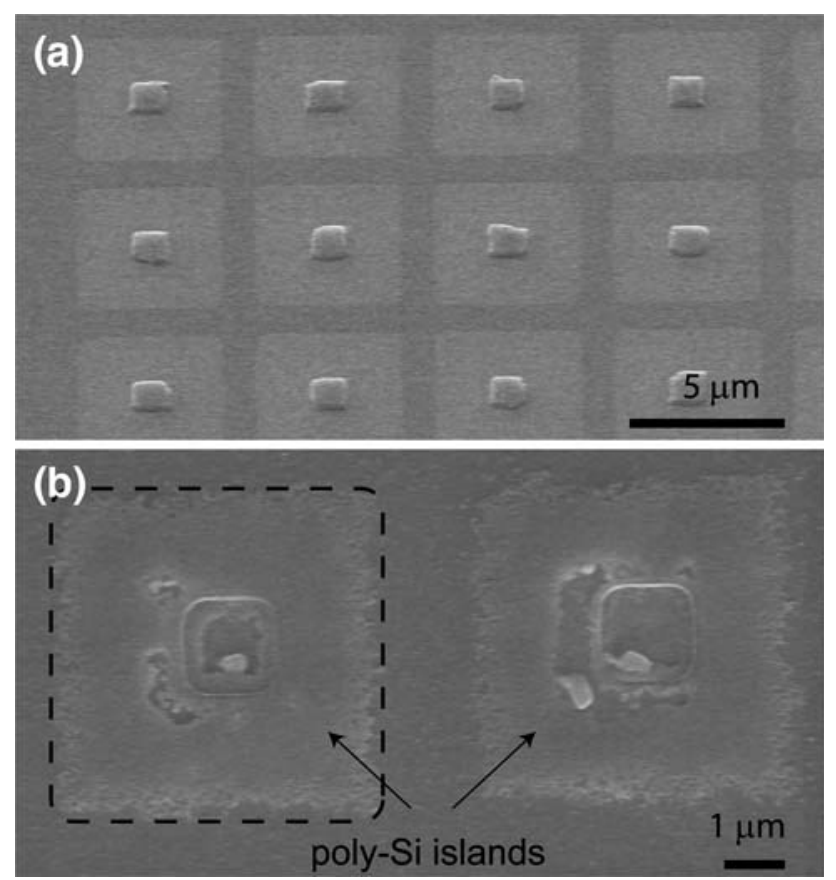

Fig. 10. SEM micrograph of contact windows to Si through: (a) thermal $\mathrm{SiO}_{2}$ grown at $850^{\circ} \mathrm{C}$, (b) $\mathrm{PECVD} \mathrm{SiO}_{2}$ deposited at $400^{\circ} \mathrm{C}$; after SPE of enough $\mathrm{Si}$ to fill the windows completely. The dashed line in (b) represents the original $\mathrm{Al} / \alpha-\mathrm{Si}$ layer stack area, which in both images can be discerned as a $\sim 5 \mu \mathrm{m} \times 5 \mu \mathrm{m}$ light-grey area around the $1 \mu \mathrm{m} \times 1 \mu \mathrm{m}$ large contact windows. In all cases, the Al transport layer has been removed selectively to $\mathrm{SiO}_{2}$ and $\mathrm{Si}$.

\section{PROCESS PARAMETER CONSIDERATIONS}

\section{Influence of the Dielectric Surface Properties}

It was shown above that the Si migration along the surface of the dielectric during SPE gives the mobile Si the chance to reach the window to the $\mathrm{Si}$ substrate and preferably crystallize there. Defects in the oxide film surface can function as preferred nucleation centers for the SPE-Si growth process, and thus the quality of this dielectric also plays a role in controlling the growth in the contact windows. The very high selectivity achieved for the sample shown in Fig. 10a was obtained by using $\mathrm{SiO}_{2}$ thermally grown at $850^{\circ} \mathrm{C}$ with a low defect density. In this case there is a practically ideal selective deposition of SPE-Si on the c-Si surface rather than the oxide surface. In contrast, if a plasma-enhanced chemical vapor deposition (PECVD) of $\mathrm{SiO}_{2}$ performed at $400^{\circ} \mathrm{C}$ is used, the situation is reversed. As can be seen in the example shown in Fig. 10b, very little SPE-Si is deposited in the contact windows and the available Si has been consumed by the deposition of polycrystalline Si on the oxide. This type of oxide apparently has a surface structure that provides a dense distribution of nucleation sites for the incoming Si that is therefore largely prevented from diffusing to the contact window. This is substantiated by previously reported atomic force microscopy analysis showing 
(a)
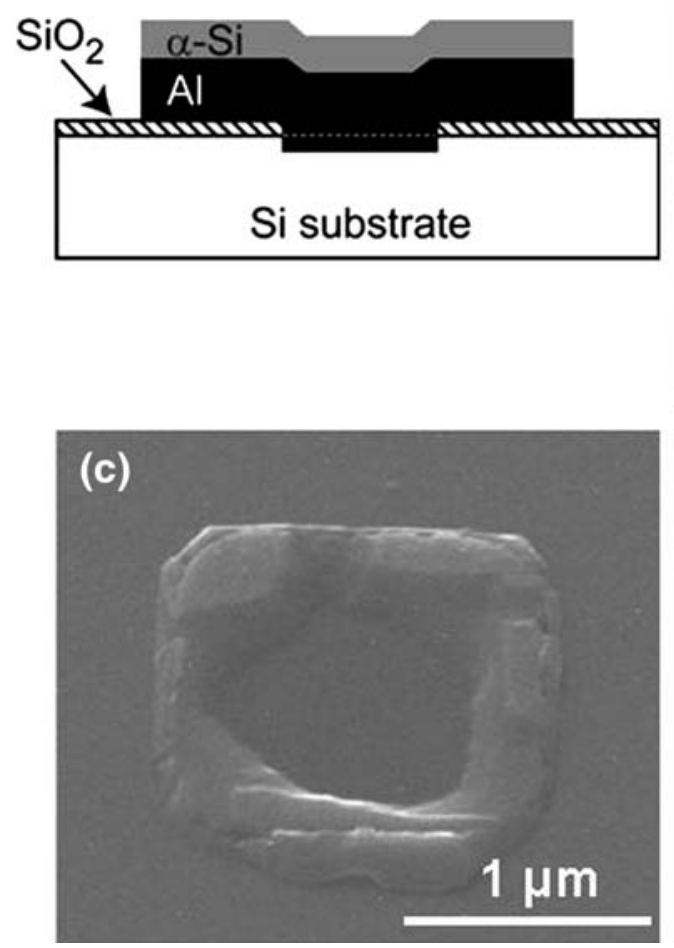

Fig. 11. (a) Schematic cross-section of 30-nm-deep contact windows etched into the Si by RIE. The dashed line shows the original Si substrate surface. The results of SPE at three different growth stages are shown in the SEM micrographs: (b) the nucleation at the corners and (c) the fast growth at the corners of $1.8 \mu \mathrm{m} \times 1.8 \mu \mathrm{m}$ contact windows, and (d) an entirely filled $1 \mu \mathrm{m} \times 1 \mu \mathrm{m}$ window. In all cases, the growth temperature was $400^{\circ} \mathrm{C}$, and the variable growth parameter was the $\mathrm{Al} / \alpha$-Si layer stack overlap of the contact window.

that the surface roughness of $\mathrm{PECVD} \mathrm{SiO}_{2}$ films can be about one order of magnitude larger than that of thermally grown $\mathrm{SiO}_{2} \cdot{ }^{26}$ Thus, for such poor-quality oxide, selective deposition in the contact windows can only be achieved if the $\mathrm{Al} / \alpha-\mathrm{Si}$ layer stack can be patterned with very little overlap of the contact window.

\section{Influence of the Contact Window Surface Treatment}

For all the above-described experiments, care was taken not to damage the Si surface of the contact windows by terminating the plasma etching of the windows in oxide with a soft landing on the $\mathrm{Si}$. The significance of this procedure was experimentally investigated by also preparing and analyzing samples where a thermally grown $\mathrm{SiO}_{2}$ was etched either by a diluted buffered HF solution (1:7), which provides a smooth $\mathrm{Si}$ growth interface, or by a trifluoromethane $\left(\mathrm{CHF}_{3}\right) /$ hexafluoroethane $\left(\mathrm{C}_{2} \mathrm{~F}_{6}\right)$ based reactive-ion etch (RIE) that is known to roughen the surface. With the latter step also a 30-nm-deep cavity was etched into the Si. In both cases, the Si surface was cleaned and the native $\mathrm{SiO}_{2}$ was removed by a 4 -min $\mathrm{HF}(0.55 \%)$ dip-etch. From SEM observations after growth and $\mathrm{Al}$ removal, examples of which are presented in
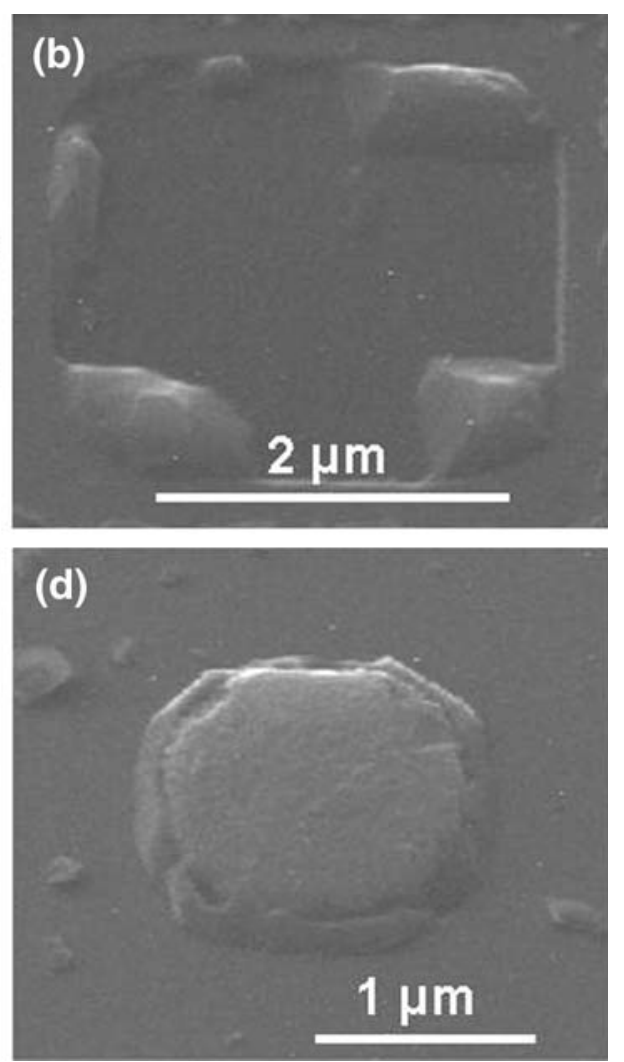

Fig. 11, it can be concluded that the damage induced by RIE at the Si growth interface influences neither the nucleation nor the growth.

\section{Geometrical Considerations}

If enough $\alpha-\mathrm{Si}$ is provided, the growth model given in the previous sections predicts that a large variety of contact window geometries can be filled completely if (1) nucleation on the surrounding oxide is avoided, and (2) the supply of Si to the central regions of the structure is not cut off by too early a filling of the perimeter regions. For an entirely selective deposition in the contact window, the quantity of $\mathrm{Si}$ supplied must correspond to the volume of the contact region to be filled. In addition, the temperature-dependent deposition time must be long enough to complete the SPE-Si deposition. Using these guidelines, lines as narrow as $65 \mathrm{~nm}$, which were defined by electron-beam lithography, were successfully filled selectively with high-quality SPE-Si. Also very large structures were filled, such as the ring-shaped contact windows shown in Fig. 12. In this case, the quality of the epitaxial interface was checked by fabricating and characterizing $p^{+}-n$ diodes. The current-voltage $(I-V)$ characteristics of a 395- $\mu \mathrm{m}$-long, $1-\mu \mathrm{m}$-wide ring diode are shown in Fig. 13 along with those of 


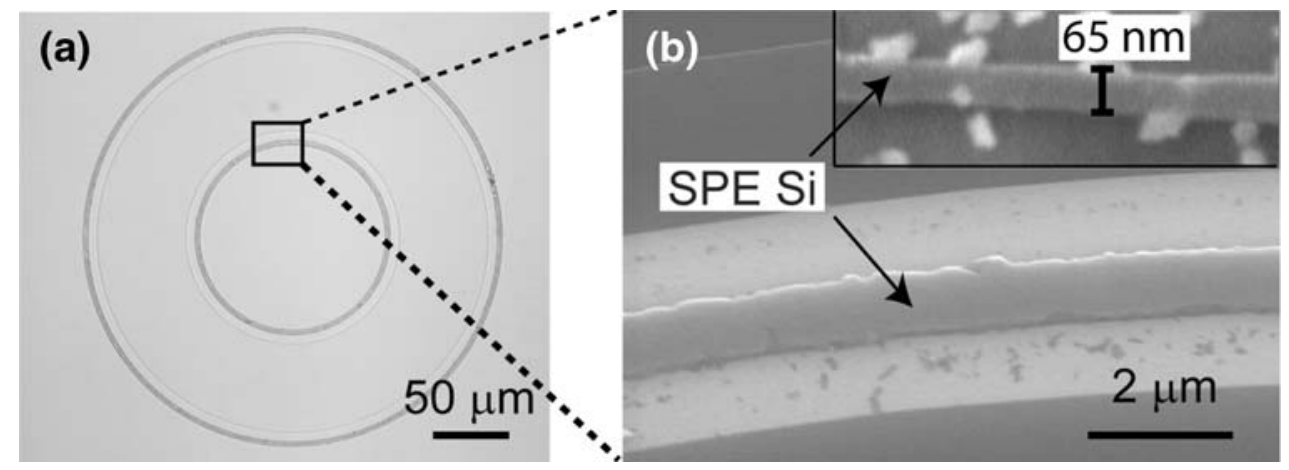

Fig. 12. SPE-Si islands selectively grown in a 395- $\mu \mathrm{m}$-long $1-\mu \mathrm{m}$-wide ring-shaped window. The thicknesses of the Al and $\alpha$-Si thin films were $100 \mathrm{~nm}$ and $75 \mathrm{~nm}$, respectively, and the $\mathrm{Al} / \alpha$-Si island to contact window width ratio was 2 . The inset shows a $65-\mathrm{nm}$-wide electron-beamdefined line-shaped contact window entirely filled in with SPE-Si.

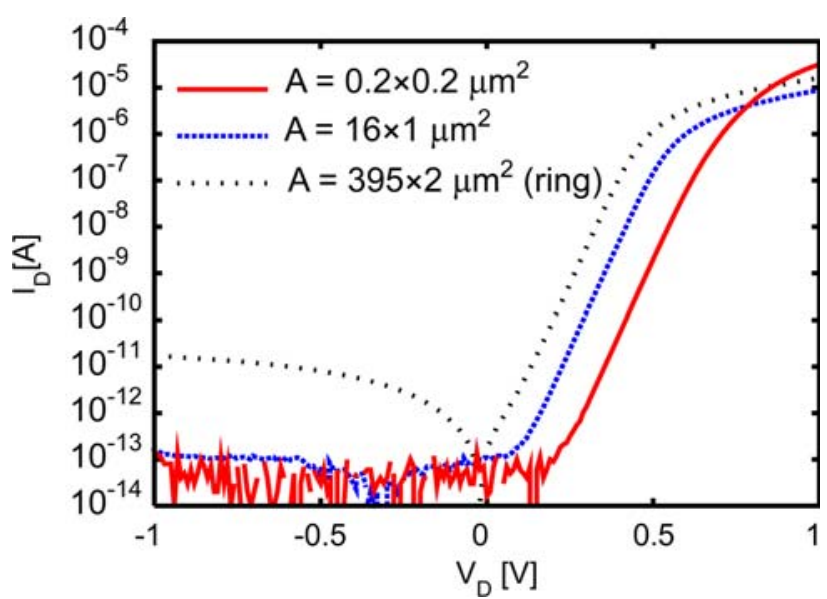

Fig. 13. $I-V$ characteristics of SPE-Si based $p^{+}-n$ diodes with three different geometries and junction areas.

medium-sized and nanoscale diodes. The same ideality factor $(n \approx 1.05)$ is achieved in all cases, with excellent uniformity and reproducibility over the wafers. Thus it can be concluded that the epitaxy is practically defect free in all cases, also at the diode perimeter.

\section{CONCLUSIONS}

It has been demonstrated by a multitude of experimental material that the proposed semiempirical model for the growth mechanisms of $\mathrm{Si}$ SPE using $\mathrm{Al}$ as a transport layer can predict the selective and complete filling of contact windows to c-Si substrates. In the early growth phase, five specific stages have been distinguished. These are, in order of occurrence: (1) formation of "free" Si at the $\mathrm{Al} / \alpha-\mathrm{Si}$ interface, (2) diffusion of $\mathrm{Si}$ along the $\mathrm{Al}$ grain boundaries, (3) nucleation at the Si substrate surface, (4) nuclei rearrangement, and (5) crystal growth.

Two factors that are shown to be important for achieving high-quality material on (100) Si are: (1) the strong preferential growth in the $\langle 100\rangle$ direction and (2) the fast diffusion of $\mathrm{Si}$ through $\mathrm{Al}$ grain boundaries and other interfaces. With the model and the much improved understanding of the other process parameters which affect the deposition mechanisms, such as the roughness of the dielectric and $\mathrm{Si}$ surfaces, it was possible to predict whether a specific contact window geometry could be filled by a single-crystalline SPE-Si island. Optimized growth parameters were successfully applied to the formation of SPE-Si grown on individual contact window areas up to several hundreds of square microns in size. Confirmation of the high quality of the resulting epitaxial filling of these windows was also obtained electrically by incorporating the SPE islands in $p^{+}-n$ diodes that showed near-ideal electrical behavior.

\section{ACKNOWLEDGEMENTS}

The authors would like to thank the staff of the DIMES-ICP cleanrooms for their continual support. G. Vastola also acknowledges fruitful discussions with Prof. L. Miglio and F. Montalenti. This research is supported by the Dutch Foundation for Fundamental Research on Matter (Stichting FOM) and performed in cooperation with the EU-FP6 project D-DotFET.

\section{OPEN ACCESS}

This article is distributed under the terms of the Creative Commons Attribution Noncommercial License which permits any noncommercial use, distribution, and reproduction in any medium, provided the original author(s) and source are credited.

\section{REFERENCES}

1. S.W. Lee and S.K. Joo, IEEE Electron. Dev. Lett. 17, 160 (1996).

2. O. Nast, S. Brehme, D.H. Neuhaus, and S.R. Wenham, IEEE Trans. Electron. Dev. 46, 2062 (1999).

3. C. Spinella and S. Lombardo, J. Appl. Phys. 84, 5383 (1998).

4. H. Qingheng, E.S. Yang, and H. Izmirliyan, Solid Stat Electron. 5, 1187 (1982). 
5. J.Y. Wang, D. He, Y.H. Zhao, and E.J. Mittemeijer, Appl. Phys. Lett. 88, 19101 (2006).

6. O. Nast and A.J. Hartmann, J. Appl. Phys. 88, 716 (2000).

7. A. Sarikov, J. Schneider, M. Muske, S. Gall, and W. Fuhs, J. Non-Cryst. Solids 352, 980 (2006).

8. Y. Civale, L.K. Nanver, P. Hadley, E.J.G. Goudena, and H. Schellevis, IEEE Electron. Dev. Lett. 27, 341 (2006).

9. Y. Civale, L.K. Nanver, and H. Schellevis, IEEE Trans. Nanotechnol. 6, 196 (2007).

10. Y. Civale, L.K. Nanver, S.G. Alberici, A. Gammon, and I. Kelly, Electrochem. Solid State Lett. 11, H74 (2008).

11. J. Schneider, A. Sarikov, J. Klein, M. Muske, I. Sieber, T. Quinn, H.S. Reehal, S. Gall, and W. Fuhs, J. Cryst. Growth 287, 423 (2006).

12. A. Hiraki, Surf. Sci. 168, 74 (1986).

13. J.A. Thornton, J. Vac. Sci. Technol. 11, 666 (1974).

14. D. He, J.Y. Wang, and E.J. Mittemeijer, Appl. Surf. Sci. 252, 5470 (2006).

15. D. He, J.Y. Wang, and E.J. Mittemeijer, J. Appl. Phys. 97, 93524 (2005)
16. D.W. Pashley, Adv. Phys. 14, 327 (1965)

17. J. Tersoff, Phys. Rev. B. 38, 9902 (1988).

18. L. Csepregi, E.F. Kennedy, J.W. Mayer, and T.W. Sigmon, J. Appl. Phys. 49, 3906 (1978).

19. R. Drosd and J. Washburn, J. Appl. Phys. 53, 397 (1982).

20. G. Wulff, Z. Kristallogr. 34, 449 (1901).

21. A. Bavard, J. Eymery, A. Pascale, and F. Fournel, Phys. Status Solidi B 243, 3963 (2006).

22. Y. Tu and J. Tersoff, Phys. Rev. Lett. 84, 4393 (2000).

23. Y. Civale, L.K. Nanver, P. Hadley, H.W. van Zeijl, E.J.G. Goudena, and H. Schellevis. Proceedings of Materials Research Society Spring Meeting, San Francisco, CA, USA, 0940-P05-04 (2006).

24. O. Nast and A.J. Hartmann, J. Appl. Phys. 88, 716 (2000).

25. O. Nast and S. Wenham, J. Appl. Phys. 88, 124 (2000).

26. G. Pandraud, T.M. Koster, C. Gui, M. Dijkstra, A. Van den Berg, and P.V. Lambeck, Sens. Actuators 85, 158 (2000). 